\title{
Loss of Estrogen Upregulates Osteoblastogenesis in the Murine Bone Marrow Evidence for Autonomy from Factors Released during Bone Resorption
}

Robert L. Jilka, Kenshiro Takahashi, Medha Munshi, Daniel C. Williams, ${ }^{*}$ Paula K. Roberson, and Stavros C. Manolagas Division of Endocrinology and Metabolism, the University of Arkansas for Medical Sciences Center for Osteoporosis and Metabolic Bone

Diseases, Geriatric Research, Education, and Clinical Center, Veterans Affairs Medical Center, University of Arkansas for Medical

Sciences, Little Rock, Arkansas 72205; and *Lilly Research Laboratories, Indianapolis, Indiana 46285

\begin{abstract}
Loss of sex steroids causes an increase in both the resorption and formation of bone, with the former exceeding the latter. Based on evidence that the increased bone resorption after estrogen loss is due to an increase in osteoclastogenesis, we hypothesized that estrogen loss also stimulates osteoblastogenesis. We report that the number of mesenchymal osteoblast progenitors in the murine bone marrow was increased two- to threefold between 2 and $8 \mathrm{wk}$ after ovariectomy and returned to control levels by $16 \mathrm{wk}$. Circulating osteocalcin, as well as osteoclastogenesis and the rate of bone loss, followed a very similar temporal pattern. Inhibition of bone resorption by administration of the bisphosphonate alendronate led to a decrease of the absolute number of osteoblast progenitors; however, it did not influence the stimulating effect of ovariectomy on osteoblastogenesis or osteoclastogenesis. These observations indicate that the increased bone formation that follows loss of estrogen can be explained, at least in part, by an increase in osteoblastogenesis. Moreover, they strongly suggest that unlike normal bone remodeling, whereby osteoblast development is stimulated by factors released from the bone matrix during osteoclastic resorption, estrogen deficiency unleashes signals that can stimulate the differentiation of osteoblast progenitors in a fashion that is autonomous from the need created by bone resorption, and therefore, inappropriate. (J. Clin. Invest. 1998. 101:19421950.) Key words: osteoblast formation -0 osteoclast formation $•$ estrogen deficiency - bone remodeling - postmenopausal osteoporosis
\end{abstract}

\section{Introduction}

Both osteoblasts and osteoclasts are derived from progenitors originating in the bone marrow: osteoblasts from the mesenchymal lineage and osteoclasts from the hematopoietic lineage $(1,2)$. The differentiation of these progenitors to either cell type is controlled by a network of growth factors and cytokines

Address correspondence to Robert L. Jilka, Division of Endocrinology and Metabolism, University of Arkansas for Medical Sciences, Slot 587, 4301 W. Markham, Little Rock, AR 72205.

Received for publication 25 June 1997 and accepted in revised form 26 February 1998.

J. Clin. Invest.

(C) The American Society for Clinical Investigation, Inc. 0021-9738/98/05/1942/09 \$2.00

Volume 101, Number 9, May 1998, 1942-1950

http://www.jci.org produced in the bone microenvironment, adhesion molecules that mediate cell-cell and cell-matrix interactions, as well as systemic hormones.

The multipotent stem cell that gives rise to osteoblasts, the colony-forming unit fibroblast (CFU-F) ${ }^{1}$ can also give rise to fibroblastic stromal cells, chondrocytes, adipocytes, and muscle cells. The existence of this common ancestor is supported by the evidence that fibroblastic colonies formed in cultures of adherent bone marrow cells can differentiate, under the appropriate stimuli, into each cell type (1). The CFU-F-derived committed osteoblast progenitors, designated as CFU-osteoblast (CFU-OB), can be identified by their ability to form a mineralized bone nodule in the presence of $\beta$-glycerophosphate $(3,4)$. Cells derived from the CFU-F colonies also provide essential support for osteoclast development (5). Although the precise stage of differentiation of the cells that support osteoclast development remains unknown, the osteoclast support cells exhibit similarities to both bone marrow stromal cells and osteoblasts; and for lack of a better term, are referred to as stromal/osteoblastic cells.

Loss of estrogens in rodents and humans stimulates bone resorption as well as bone formation. The former of course exceeds the latter, thus causing loss of bone (6-10). Earlier studies have revealed that loss of estrogen in mice stimulates osteoclast formation. This phenomenon is apparently mediated by increased production and/or action of IL-6, and is probably responsible for the increased bone resorption that ensues after loss of estrogen, as blockade of IL-6 prevents the upregulation of osteoclastogenesis, and IL-6-deficient mice fail to exhibit increased osteoclastogenesis or bone loss $(8,11)$. IL-6-mediated upregulation of osteoclast development and bone loss occur also as a result of orchidectomy in mice (12). Consistent with this evidence, estrogen and androgen suppress the expression of the genes encoding IL-6 (12-18) as well as the two subunits of the IL-6 receptor, gp80 and gp130 (19); and removal of the suppressive effect of estrogen upregulates the expression of these genes in the murine bone marrow (19).

The increase in bone formation after menopause or acute sex steroid deficiency due to gonadectomy in animals and humans has been well documented by histomorphometric studies, and can be monitored by the elevated level of circulating osteoblast-derived proteins such as osteocalcin and bone-specific alkaline phosphatase $(6-9,20)$. Based on the evidence that the increase in bone resorption is due to an increase in osteoclastogenesis in the marrow, we have investigated here the

1. Abbreviations used in this paper: $\mathrm{BV}$, bone volume; CFU-F, colony-forming unit fibroblast; CFU-GM, colony-forming unit granulocytes/macrophages; CFU-OB, colony-forming unit osteoblast; $\mathrm{LDH}$, lactate dehydrogenase; TRAPase, tartrate-resistant acid phosphatase; TV, total volume. 
possibility that ovariectomy causes an increase in osteoblastogenesis as well. We present evidence that ovariectomy in mice causes an increase in the number of CFU-F and CFU-OB in the bone marrow, and that these changes are temporally associated with increased osteoblast activity as measured by changes in serum osteocalcin. Furthermore, the changes in osteoblastogenesis occur at approximately the same time that osteoclastogenesis is increased and bone loss occurs. Finally, using alendronate as a means of preventing osteoclastic bone resorption $(9,21)$, we show that the upregulation of osteoblastogenesis and osteoclastogenesis after loss of estrogen is independent of bone resorption.

\section{Methods}

Mice. Swiss Webster female mice (Taconic Farms Inc., Germantown, NY, or Harlan Sprague Dawley, Inc., Indianapolis, IN) weighing 26$30 \mathrm{~g}$ and $\sim 10-12$-wk-old, were sham-operated, or ovariectomized. In some experiments, mice received daily injections (subcutaneously) of $0.25 \mathrm{mg} / \mathrm{kg}$ of alendronate (4-amino-1-hydroxybutylidene-1,1-bisphosphonate, obtained from C.W.G.M. Löwik, University Hospital, Leiden, The Netherlands) dissolved in saline, beginning $1 \mathrm{~d}$ before surgery. Animals were killed by heart puncture at various times after the operation, as indicated in the figure legends. Serum was obtained from the tail vein or during heart puncture, and was frozen at $-20^{\circ} \mathrm{C}$ for later determination of osteocalcin by radioimmunoassay (Biomedical Technologies, Inc., Stoughton, MA). In some experiments, urine was collected between 5 p.m. and 8 a.m. using a metabolic cage, and frozen for later determination of creatinine (Sigma Chemical Co., St. Louis, MO) and deoxy-pyridinoline cross-links (Pyrilinks-D; Metra Biosystems, Mountain View, CA). In all experiments, the success of ovariectomy was confirmed by establishing a decrease in uterine wet weight. The femurs were removed for the harvest of bone marrow cells or for analysis of cancellous bone. Marrow cells were obtained by cutting the ends of the femur and flushing the marrow with $5 \mathrm{ml}$ of phenol red-free $\alpha$ MEM (GIBCO BRL, Gaithersburg, MD) containing $10 \%$ FBS (Hyclone, Logan, UT), using a syringe fitted with a 25 gauge needle. After the cells were rinsed and resuspended using a 23 gauge needle to obtain a single cell suspension, the nucleated cell count was determined using a Coulter Counter (Coulter Corp., Miami, FL).

Assay of osteoblast progenitors. Freshly isolated marrow cells were seeded at $1.5 \times 10^{6}$ or $2.5 \times 10^{6}$ cells per $10-\mathrm{cm}^{2}$ well for the determination of CFU-F and CFU-OB, respectively, and maintained in phenol red-free $\alpha$ MEM containing $15 \%$ preselected FBS, $50 \mu \mathrm{M}$ ascorbic acid, and $10 \mathrm{mM} \beta$-glycerophosphate; one-half of the medium was replaced every $5 \mathrm{~d}$. For the determination of CFU-F, cells were cultured for $10 \mathrm{~d}$, and then stained for alkaline phosphatase and counterstained with hematoxylin. Colonies of cells containing a minimum of 20 cells were designated as CFU-F. For the determination of CFU-OB, the cultures were maintained for $25-28 \mathrm{~d}$, fixed in $50 \%$ ethanol and $18 \%$ formaldehyde, and then stained for boney deposits using $2 \%$ alizarin red or Von Kossa staining. Where indicated, $1 \mathrm{mM}$ ascorbate-2-phosphate was used to stimulate osteoblast differentiation and mineralization, instead of the combination of ascorbic acid and $\beta$-glycerophosphate. Preliminary studies indicated that there was a linear correlation between the number of marrow cells seeded and the number of CFU-F or CFU-OB colonies formed.

Assay of individual CFU-F colonies. The number of cells and alkaline phosphatase activity in individual CFU-F colonies was quantified as previously described (22). Briefly, between 6,000 and 20,000 marrow cells per well were seeded in a 96-well plate $(n=168$ wells per assay), and cultured as described above for the determination of CFU-F. After fixation, lactate dehydrogenase activity (LDH) was determined by the rate of reduction of 3-(4,5-dimethylthiazol-2-yl)-5(3-carboxymethoxyphenyl)-2-(4-sulfophenyl)-2H-tetrazolium, inner salt (MTS). LDH activity was used as an index of the number of cells present in the well, and was expressed as MTS units, which were defined as the change in $\operatorname{OD}^{490}\left(\times 10^{3}\right)$ per minute. Alkaline phosphatase activity was then determined using kit No. 104 (Sigma Chemical Co.). $1 \mu \mathrm{U}$ of activity was defined as that amount of enzyme capable of hydrolyzing $1 \mathrm{pmol}$ of $p$-nitrophenylphosphate per minute at room temperature. Data on cell number (LDH activity) and alkaline phosphatase content were analyzed only in the case of wells that contained a single colony, determined by microscopic examination.

Assay of osteoclast progenitors. For the determination of CFUgranulocytes/macrophages (CFU-GM), triplicate cultures of marrow cells were established by plating $10^{5}$ cells in $35-\mathrm{mm}$ tissue culture dishes containing $1.5 \mathrm{ml}$ of semisolid methycellulose medium with pokeweed mitogen-stimulated spleen cell conditioned medium (No. M3430; Stem Cell Technologies, Inc., Vancouver, British Columbia, Canada). After $7 \mathrm{~d}$, CFU-GM colonies ( $>50$ cells) were enumerated. The number of CFU-GM formed per femur was calculated using the marrow cell yield. The number of CFU-GM in S-phase ("cycling" CFU-GM) was determined after killing cells in S-phase by incubation for 30 minutes at $37^{\circ} \mathrm{C}$ in medium containing $50 \mu \mathrm{C} / \mathrm{ml}$ [methyl${ }^{3} \mathrm{H}$ ]thymidine $(75 \mathrm{Ci} / \mathrm{mmol}$ ) before establishing the culture. The number of cycling CFU-GM per femur was determined by subtracting the number of CFU-GM colonies per femur formed after preincubation with [methyl- $\left.{ }^{3} \mathrm{H}\right]$ thymidine from the number of colonies formed per femur without preincubation.

Osteoclastogenesis in ex vivo cultures of bone marrow cells was carried out as previously described $(11,13)$. Briefly, marrow cells were cultured at $1.5 \times 10^{6}$ per $2-\mathrm{cm}^{2}$ well on $13-\mathrm{mm}$ round Thermanox disks and maintained for $8 \mathrm{~d}$ in the presence of $10 \%$ FBS in $\alpha$ MEM supplemented with $10^{-8} \mathrm{M} 1,25(\mathrm{OH})_{2} \mathrm{D}_{3}$ (provided by Dr. Milan Uskokovic, Hoffman-LaRoche, Nutley, NJ). At the end of the experiment, cells were processed for autoradiographic detection of bound ${ }^{125}$ I-labeled calcitonin and stained for tartrate-resistant acid phosphatase (TRAPase). All cells expressing both TRAPase and autoradiographic grains due to bound ${ }^{125} \mathrm{I}$-calcitonin were enumerated, including mononucleated and multinucleated cells. In view of the fact that many osteoclasts in murine bone possess only one nucleus (22), it is impossible to distinguish between preosteoclasts and mononuclear osteoclasts in ex vivo cultures of murine bone marrow cells. Therefore, TRAPase-positive and CT receptor cells were designated as osteoclastic cells.

Analysis of trabecular bone. Femurs were fixed in neutral buffered formalin, and cut at the midshaft and on either side of the patellar groove, using a precision cutting diamond saw. Bones were dehydrated using ethanol and embedded in glycol methacrylate. Then a $100-\mu \mathrm{m}$ ground section was prepared in the mid-sagittal plane through the distal metaphysis. Calcified areas were detected by Von Kossa staining. The area of the central portion of the metaphysis, "total volume" (TV), and the area of this region occupied by calcified cancellous bone in the secondary spongiosa, "bone volume" (BV), was determined using a Bioquant System IV image analysis system (Nashville, TN). These data were used to calculate the percentage of cancellous bone in the distal femur (BV/TV).

Statistics. Data were analyzed using SigmaStat (Jandel Scientific, San Rafael, CA) or NCSS (Kaysville, UT) statistical software packages. Student's $t$ test or ANOVA was performed after establishing homogeneity of variances and normal distribution of the data. Dunnet's test or Student-Neuman-Keuls test was used to estimate the level of significance of differences between means. Significant differences in colony size distribution were determined using the Kolmogorov-Smirnov test. In experiments to compare the effect of ovariectomy on bone cell progenitors at different times after the operation, the effect of ovariectomy was calculated as ratio of progenitors from ovariectomized mice to that from sham-operated mice. This was done to eliminate variation due to the change in age of the mice during the experiment. In addition, the three time course experiments were conducted over a 3-yr period; therefore, different lots of serum and cyto- 


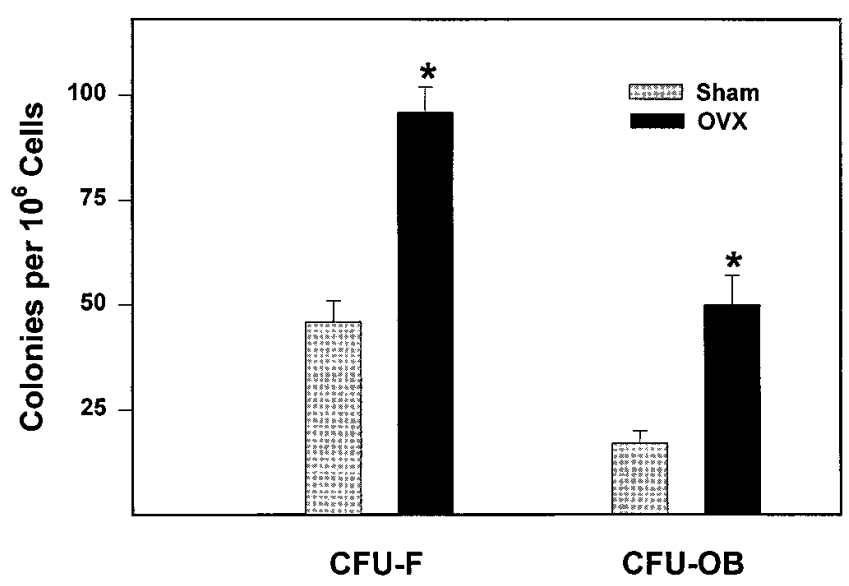

Figure 1. Effect of ovariectomy on osteoblast progenitors. Mice were sham-operated or ovariectomized. $4 \mathrm{wk}$ after the operation, animals were killed, femoral marrow cells were isolated, and cells from each treatment group were pooled ( $n=4$ per group). Quadruplicate parallel cultures were established for the determination of CFU-F or CFU$\mathrm{OB}$, as described in Methods. Bars represent the mean ( $\pm \mathrm{SD})$ number of colonies formed per $10^{6}$ marrow cells seeded in the cultures. Data were analyzed by Student's $t$ test. $* P<0.05$ versus sham-operated animals. There was no difference in the ratio of the number of CFU-F to CFU-OB colonies in cultures from sham-operated and ovariectomized mice as determined by $z$ test.

kines had to be used. The standard error of the ratio of means was calculated using established methods (23).

\section{Results}

The results of experiments examining the effect of estrogen deficiency on progenitors able to form CFU-F and CFU-OB colonies in ex vivo bone marrow cell cultures are shown in Fig. 1. As compared to cultures from sham-operated control animals, cultures of bone marrow cells obtained 3 wk after ovariectomy exhibited two- to threefold higher numbers of CFU-F determined after $10 \mathrm{~d}$ of culture, or CFU-OB determined after $28 \mathrm{~d}$ of culture. In a previous study, we observed a similar increase in osteoblast progenitors in orchidectomized mice (24). When expressed per $10^{6}$ cells seeded, the absolute number of CFU-OB colonies was approximately one half of the number of CFU-F colonies. More important, the ratio of CFU-OB colonies to CFU-F colonies was similar in cultures from sham-operated and ovariectomized mice ( 0.37 and 0.52 , respectively, not significantly different by $z$ test). This suggests that the difference in absolute numbers of colonies was due to a different number of progenitors at the beginning of the culture.

To examine whether the changes induced by ovariectomy in colony numbers in ex vivo cultures were the result of an in vivo effect on the commitment of mesenchymal stem cells toward the osteoblast lineage, we proceeded to determine the level of alkaline phosphatase activity, an early marker of osteoblast differentiation (1), within individual colonies. Analysis of features exhibited by a single CFU-F colony was accomplished using an assay we have recently developed that allows the estimation of the number of cells within a colony simultaneously with determination of alkaline phosphatase activity (22). As seen in Fig. 2, CFU-F colonies exhibit considerable variation in size and the intensity of staining for alkaline phosphatase. Based on extensive studies of other cell lineages that undergo proliferation and differentiation during development from multipotent progenitors, many aspects of which have been confirmed in the case of osteoblastogenesis $(1,25)$, we reasoned that small colonies develop from more committed progenitors, which have less proliferative potential, and that

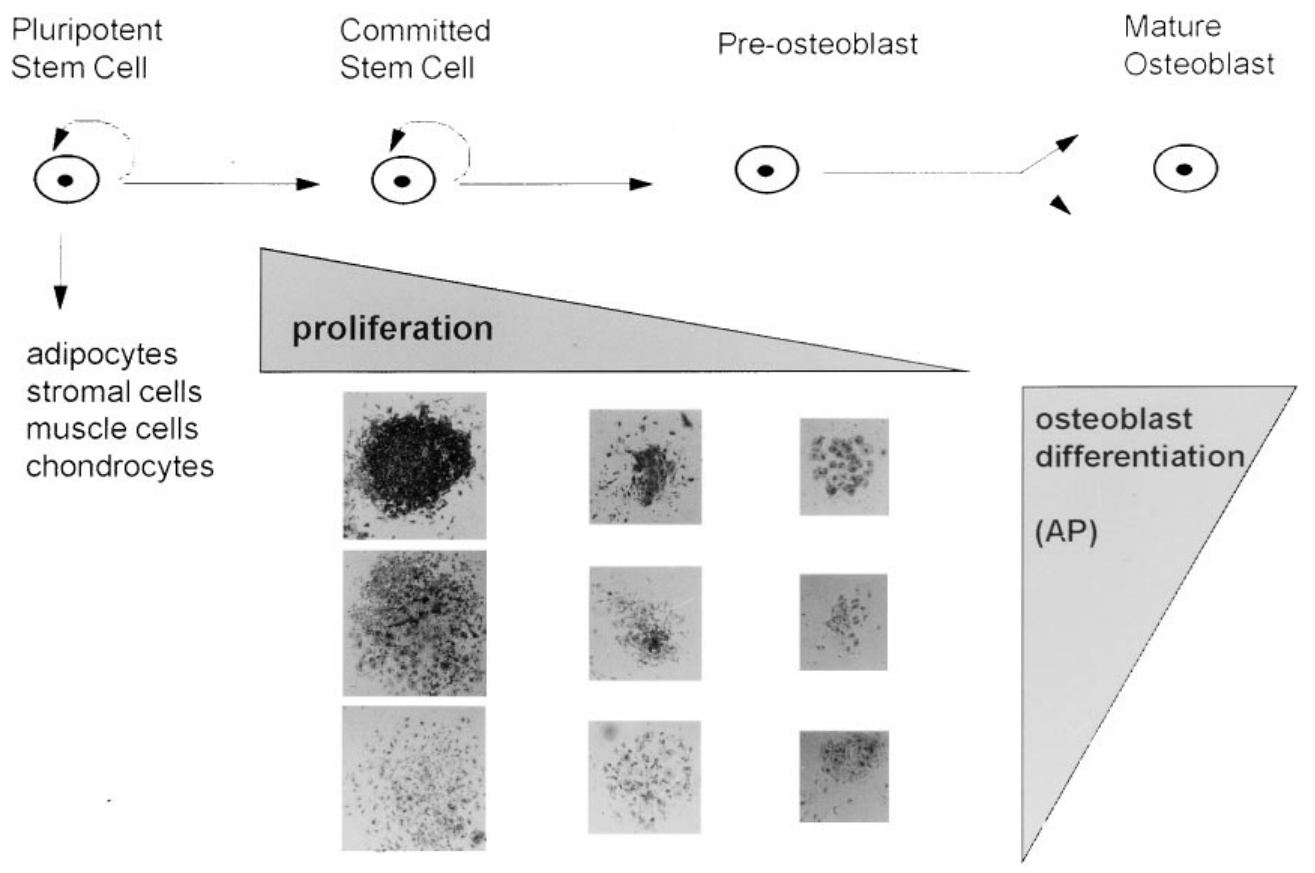

Figure 2. Variation in size and alkaline phosphatase content of CFU-F colonies: relationship to osteoblastogenesis. The upper portion of the figure depicts a model of osteoblast differentiation from mesenchymal stem cells of the bone marrow $(1,25)$. Photomicrographs in the lower part of the figure show representative CFU-F colonies of varying size and degree of staining for alkaline phosphatase (purple stain). Magnification $=40$. The upper triangle represents variation in the ability of osteoblast progenitors to proliferate in ex vivo cultures, with early progenitors demonstrating high proliferative capacity, and committed preosteoblastic cells exhibiting low proliferative capacity. The triangle on the right side of the figure represents variation in the expression of alkaline phosphatase $(A P)$ with committed

preosteoblastic cells expressing high levels of the enzyme. In this model, large colonies with high levels of alkaline phosphatase are formed from pluripotent and committed stem cells that divide and subsequently differentiate into osteoblasts during culture, whereas small colonies with high levels of alkaline phosphatase arise from committed preosteoblastic cells. 

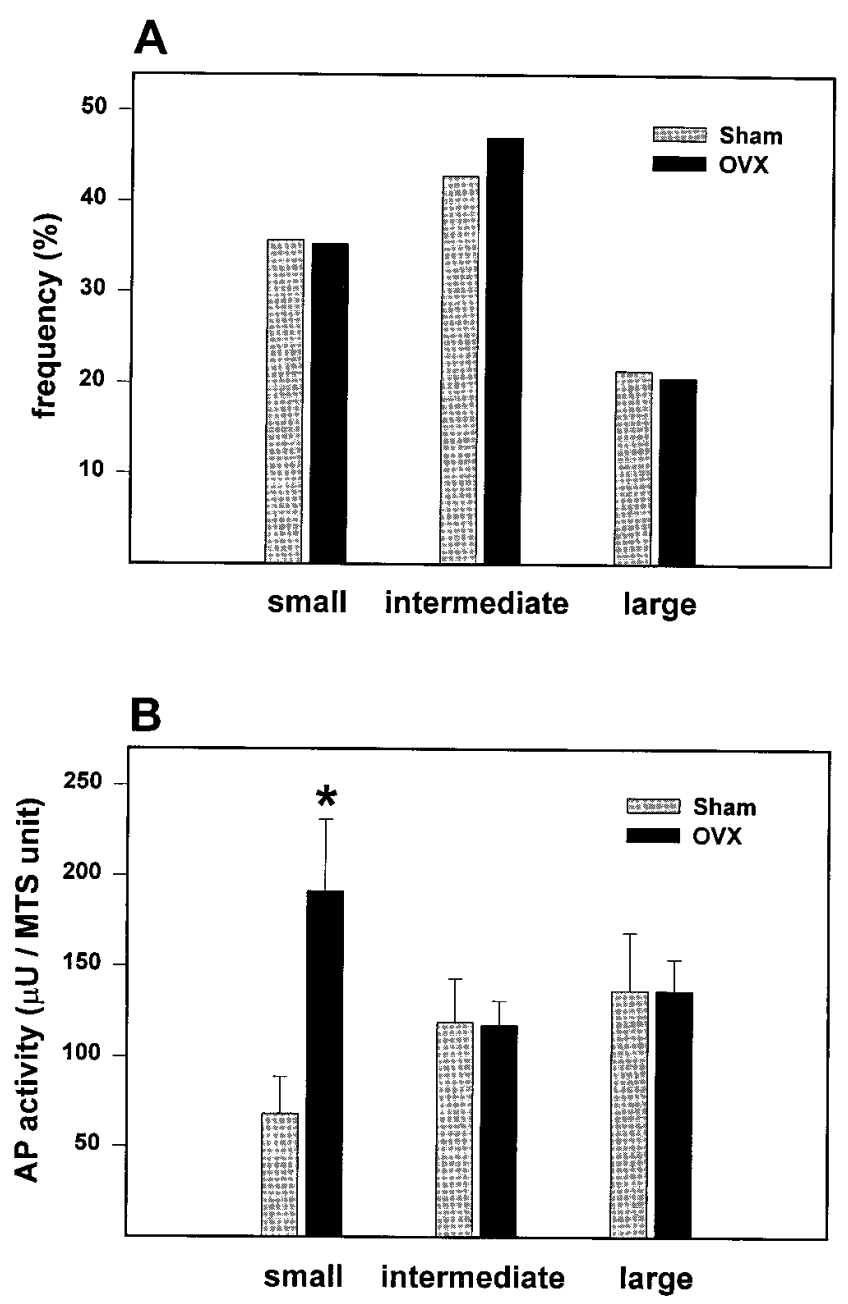

Figure 3. Effect of ovariectomy on colony size and alkaline phosphatase activity in individual CFU-F colonies. Mice were sham-operated or ovariectomized. $3 \mathrm{wk}$ after the operation, animals were killed, femoral marrow cells were isolated, and cells from each treatment group were pooled. Ex vivo cell cultures were then established for the determination of $(A)$ colony size and $(B)$ alkaline phosphatase content of individual CFU-F colonies, as described in Methods. In $A$, bars represent the percentage of small ( $\leq 0.2$ MTS units), intermediate ( $>0.2$ and $\leq 0.8$ MTS units) or large ( $>0.8$ MTS units) colonies. There was no effect of estrogen status on CFU-F colony size as determined by the Kolmogorov-Smirnov test ( $n=42$ colonies from shamoperated mice, and 34 colonies from ovariectomized mice). In $B$, bars represent the mean $( \pm$ SEM) alkaline phosphatase activity in CFU-F colonies ( $n=5-15$ per group). $* P<0.05$ versus sham operation as determined by ANOVA after log transformation to achieve equivalent variances.

large colonies arise from less differentiated progenitors with high proliferation capacity (Fig. 2). Thus, smaller CFU-F colonies with the most intense staining for alkaline phosphatase must contain more differentiated osteoblastic cells as compared to small colonies with less intense alkaline phosphatase staining.

Cultures from ovariectomized mice had the same microscopic cell features when compared to cultures from sham-operated controls. Moreover, the distribution of different colony sizes (i.e., small, medium, and large) was indistinguishable be- tween the two groups, suggesting that ovariectomy did not cause a change in the proliferative potential of the progenitors (Fig. $3 A$ ). This finding was unlike our previous observation of smaller CFU-F colonies in ex vivo cultures from marrow of mice with defective osteoblast development and osteopenia, compared to CFU-F colonies from control mice (22).

Alkaline phosphatase activity was increased by two- to threefold in small colonies from ovariectomized mice, as compared to small colonies from sham-operated animals (Fig. 3 $B)$. On the other hand, alkaline phosphatase activity in intermediate size and large colonies was unaffected by the estrogen status of the donor animal. These findings are consistent with the idea that acute estrogen deficiency causes a shift in the commitment of mesenchymal progenitors toward the osteoblast phenotype.

Evidence from both animal and human studies indicates that the effect of estrogen loss on bone metabolism changes with time (26-28). Therefore, we investigated the time course of the changes in CFU-F numbers after ovariectomy over a period of $210 \mathrm{~d}$, by determining CFU-F numbers in ex vivo bone marrow cultures obtained from ovariectomized animals at progressively longer time intervals after the operation (Fig. $4 A$ ). CFU-F numbers were unchanged at 3 and $7 \mathrm{~d}$, but were significantly elevated at $14 \mathrm{~d}$ after ovariectomy. They remained significantly higher than the sham-operated controls as long as $56 \mathrm{~d}$, but at later time points (115 and $210 \mathrm{~d}$ after ovariectomy), CFU-F numbers from ovariectomized animals were indistinguishable from those of sham-operated mice. Similar results were obtained in a second time course experiment, in which both CFU-F and CFU-OB numbers were examined over a period of $57 \mathrm{~d}$ after sham operation or ovariectomy (Fig. $4 B$ ). However, unlike the experiment shown in Fig. $4 A$, an increased number of CFU-F at 2 wk after ovariectomy was not observed in this second experiment. The effect of ovariectomy on CFU-F and CFU-OB numbers was the same regardless of whether ascorbate-2-phosphate or the combination of ascorbic acid and $\beta$-glycerophosphate was used to stimulate osteoblast differentiation and mineralization (data not shown).

Taking advantage of the finding that CFU-F and CFU-OB numbers change with time after ovariectomy, we next sought to determine whether these changes have an impact on osteoblast biology in vivo by searching for parallel temporal changes in osteoblast activity in the whole animal. To this end, we determined the circulating level of osteocalcin, a protein produced by osteoblasts and used extensively as a marker of osteoblastic activity, at various time points after ovariectomy, roughly covering the same period of time that we had determined CFU-F numbers. Similar to our observations on bone marrow progenitors, we found that ovariectomy caused an approximately twofold increase in the level of osteocalcin in the serum as early as $14 \mathrm{~d}$ after the operation. Osteocalcin levels were elevated as late as $56 \mathrm{~d}$ after ovariectomy (Fig. 5). However, by $180 \mathrm{~d}$, the levels of osteocalcin in ovariectomized mice were indistinguishable from sham-operated controls.

In view of the fact that ovariectomy leads to an increase in rate of bone remodeling and that, as in the case of the boneforming effects of estrogen deficiency, the rate of resorption may be changing with time after loss of ovarian function, we determined changes in osteoclast progenitors in the bone marrow and their temporal relationship with the rate of bone loss. Early hematopoietic osteoclast progenitors, assessed as CFU$\mathrm{GM}$, increased by approximately twofold as early as $7 \mathrm{~d}$ after 


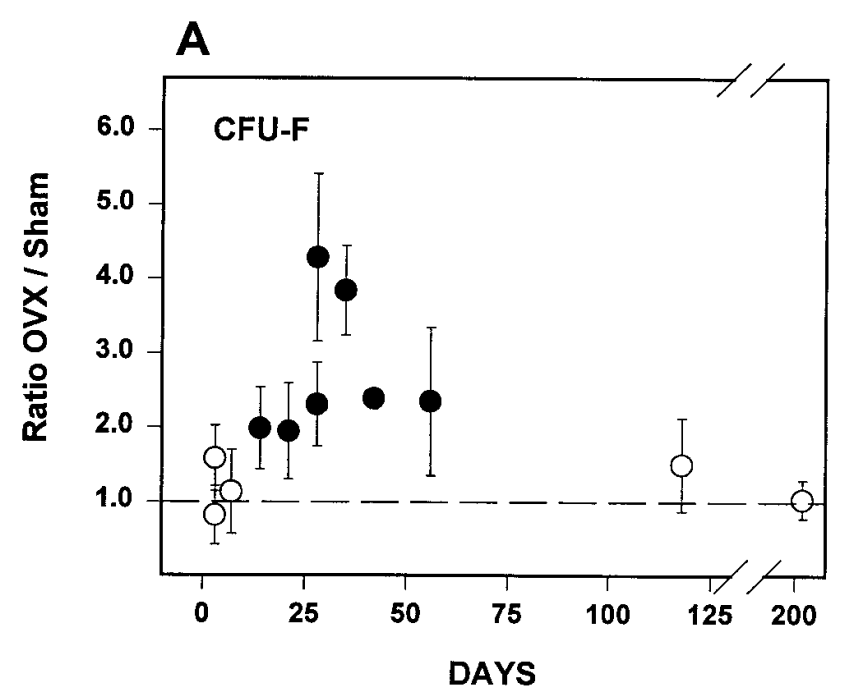

B

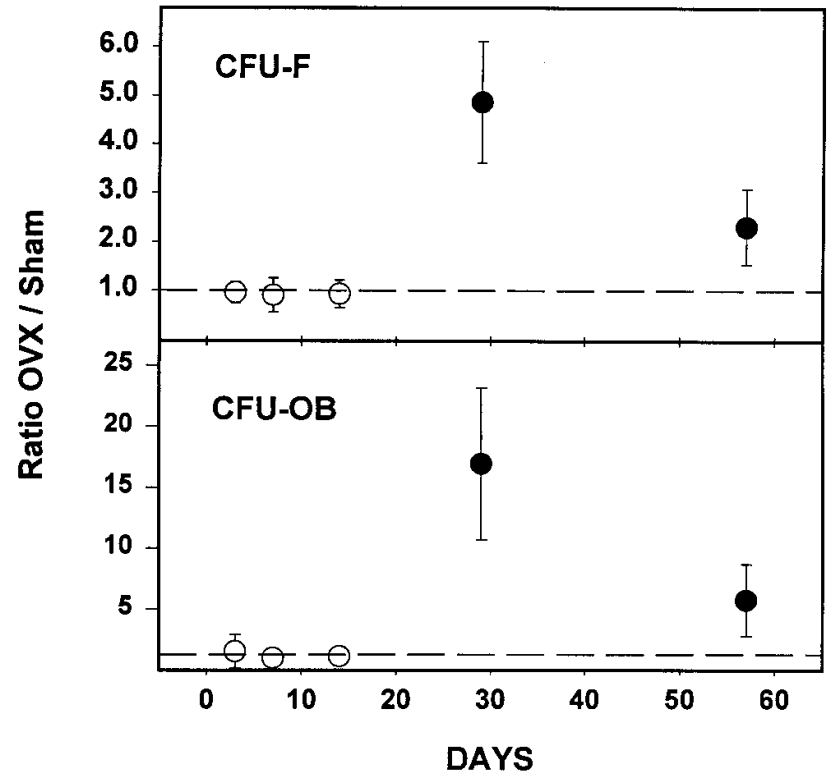

Figure 4. Time course of change in osteoblast progenitors in the bone marrow after ovariectomy. (A) Mice were either sham-operated or ovariectomized ( $n=4-6$ per group), and killed 3, 7, 14, 21, 28, 35, 42, 56,118 , or 205 d later. Replicate experiments were carried out at 3 and $28 \mathrm{~d}$. Marrow cell cultures were established for the determination of CFU-F as described in Methods. $(B)$ Mice were either shamoperated or ovariectomized ( $n=6$ per group), and killed $3,7,14,28$, or $56 \mathrm{~d}$ later. Marrow cells were established for the determination of CFU-F and CFU-OB as described in Methods. The data shown are the ratio of the mean number of CFU-F or CFU-OB per femur found in ovariectomized mice and that found in sham-operated mice, at each time point. The mean number of osteoblast progenitors per femur in sham-operated animals among the experiments shown ranged between 400 and 2,500 for CFU-F, and 100 and 800 for CFU-OB. Er ror bars represent the calculated SEM of the ratio, derived from the SEM values of the means used to calculate the ratio (23). A statistically significant effect of ovariectomy on the number of CFU-F per femur, determined using Student's $t$ test, is indicated by the closed circles $(P<0.05)$; and lack of a statistically significant effect is indicated by open circles.

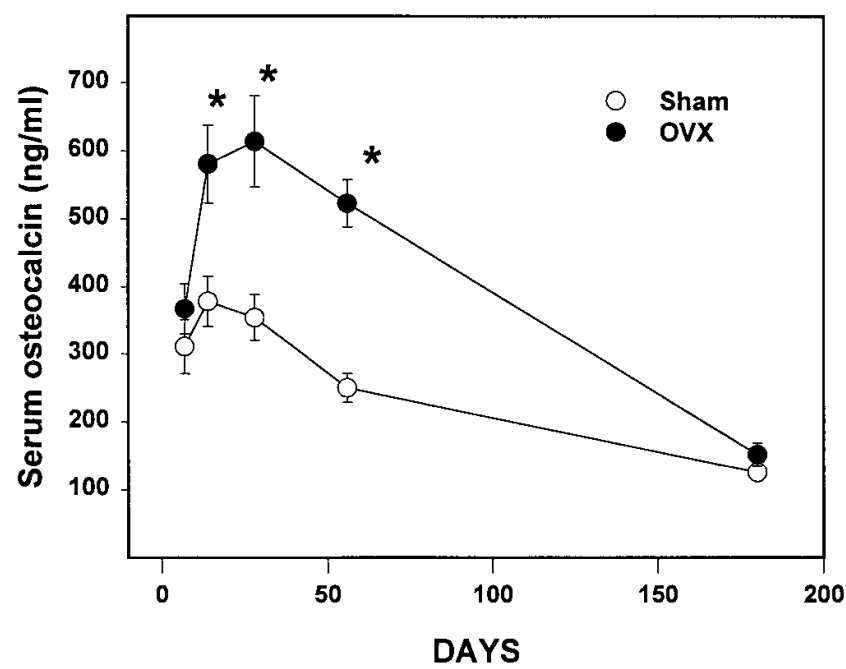

Figure 5. Time course of change in serum osteocalcin in mice after ovariectomy. Mice were sham-operated or ovariectomized, and killed $7,14,28,56$, or 180 d later. Serum was collected for determination of osteocalcin by RIA as described in the Methods section. Each data point represents the mean $( \pm \mathrm{SEM}) \mathrm{ng} / \mathrm{ml}$ of osteocalcin $(n=12-18$ animals per group). $* P<0.05$ versus sham-operated animals.

the operation, and returned to levels similar to that of shamoperated animals by 28-35 d (Fig. 6). The number of CFU-GM in S-phase (cycling CFU-GM), a sensitive indicator of exposure to IL-6 (12), was also increased after ovariectomy and followed the same temporal pattern as CFU-GM. Ovariectomy also induced a three- to fourfold increase in osteoclastogenesis in ex vivo marrow cultures, as we and others had shown previously $(11,29)$. This change followed the same time course as the increase in CFU-GM; however, unlike CFU-GM, osteoclastic cell formation in ex vivo cultures remained elevated at 28 and $56 \mathrm{~d}$ after the operation, before declining to the level exhibited by sham-operated animals at 115 and $210 \mathrm{~d}$. Over the same period of time, cancellous bone volume was significantly reduced in ovariectomized mice, compared to that of shamoperated controls (Fig. 7). A significant decrease in trabecular bone volume was detected as early as $7 \mathrm{~d}$ after the operation and reached a plateau by $4 \mathrm{wk}$ after ovariectomy. Sham-operated mice also exhibited a decline in femoral cancellous bone during this experiment, albeit much smaller than that seen in ovariectomized mice. This later phenomenon has been observed previously in the rat, but its cause remains unclear (27).

Finally, we investigated whether increased osteoblastogenesis was dependent on factors released from the bone matrix during the increased resorption caused by increased osteoclastogenesis. To do this, sham-operated or ovariectomized mice were treated with either vehicle or the potent antiresorptive agent alendronate $(0.25 \mathrm{mg} / \mathrm{kg}$ per day) beginning $1 \mathrm{~d}$ before the operation, and the number of osteoblast and osteoclast progenitors in the marrow was determined 4 wk later. Administration of alendronate suppressed the level of urinary deoxypyridinoline, a measure of bone resorption (20), in shamoperated animals; moreover, alendronate prevented the ovariectomy-induced increases in urinary deoxy-pyridinoline and serum osteocalcin (Fig. 8). Strikingly however, the stimulatory effect of ovariectomy on osteoblastogenesis or osteo- 


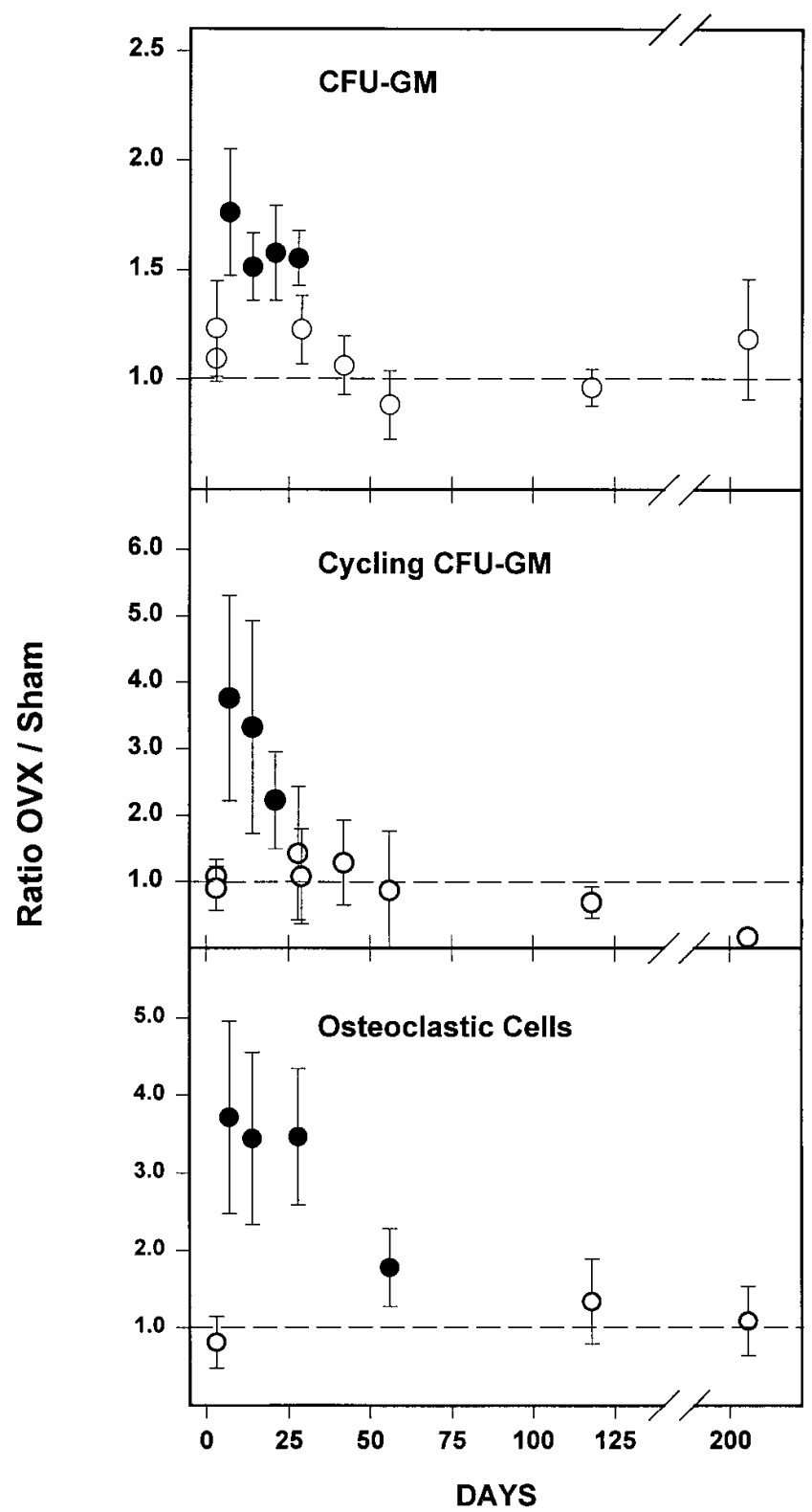

Figure 6. Time course of change in osteoclast progenitors in the bone marrow after ovariectomy. Marrow cells obtained from the same animals ( $n=4-6$ per group) used for the experiments shown in Fig. $4 A$ were placed into ex vivo culture for the determination of CFU-GM, cycling CFU-GM, and osteoclastic cell formation, as described in Methods. Replicate experiments were carried out at 3 and $28 \mathrm{~d}$, and at some time points the osteoclastic cell formation assay was omitted. The data shown are the ratio of the mean number of progenitors per femur found in ovariectomized mice and that found in sham-operated mice. The mean number of progenitors per femur in sham-operated animals among the experiments shown ranged between 10,000 and 60,000 for CFU-GM, 2,000 and 13,000 for cycling CFU-GM, and 2,500 and 7,600 for osteoclastic cells. Error bars represent the calculated SEM of the ratio, derived from the SEM values of the means used to calculate the ratio (23). A statistically significant effect of ovariectomy on the number of osteoclast progenitors per femur, determined using Student's $t$ test, is indicated by the closed circles $(P<0.05)$. Lack of a statistically significant effect is indicated by the open circles.

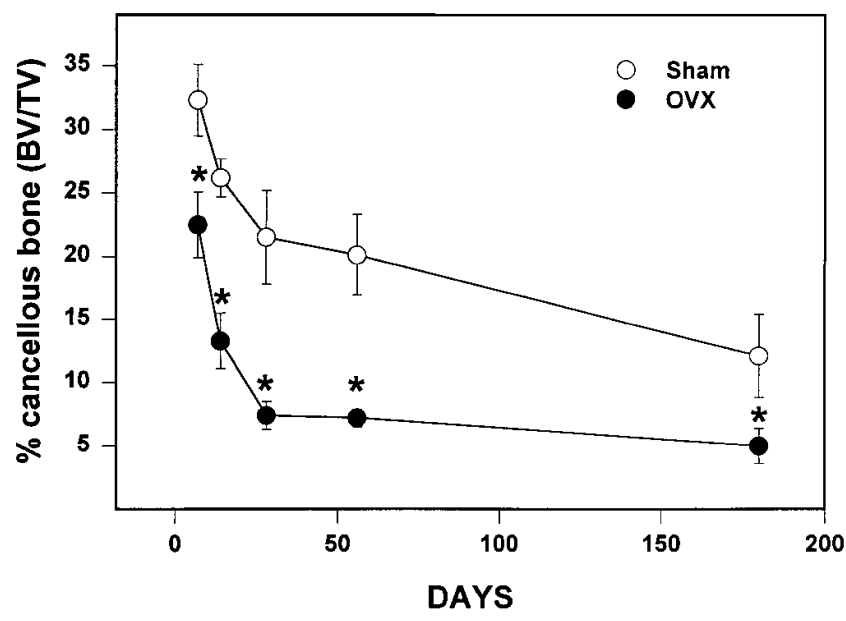

Figure 7. Time course of bone-loss mice after ovariectomy. Femurs from the mice of the experiment shown in Fig. 5 were analyzed to determine the amount of cancellous bone present in the secondary spongiosa of the distal metaphysis as described in Methods. Each data point represents the mean $( \pm \mathrm{SEM})$ percentage area occupied by cancellous bone $\left(B V / T V ; n=12-18\right.$ animals per group). ${ }^{*} P<0.05$ versus sham-operated animals.

clastogenesis, as evidenced by changes in CFU-OB and osteoclast progenitor numbers, was not affected by administration of alendronate. Nonetheless, the absolute number of CFU-OB was decreased by alendronate in both sham-operated and ovariectomized animals.

\section{Discussion}

The maintenance of a balance between bone resorption and formation during normal bone remodeling requires that the proper number of mature osteoblasts and osteoclasts is produced to meet the needs of the remodeling process. The results of the present studies demonstrate that estrogen loss increases the number of mesenchymal progenitors that are capable of committing to the osteoblast lineage in the murine bone marrow, and that these changes are temporally linked with increased osteoblast activity. These findings are consistent with evidence suggesting that estrogen deficiency affects osteoblast differentiation in the rat $(30,31)$. Moreover, they elucidate the cellular changes underlying the increased bone formation associated with loss of estrogen. Taken together with earlier observations that increased osteoclastogenesis leads to increased bone resorption in estrogen deficiency (11), and that decreased osteoblastogenesis is associated with decreased bone formation and bone mass in a murine model of osteopenia (22), our results provide compelling evidence that the orderly births of osteoclasts and osteoblasts from their respective progenitors in the bone marrow are essential determinants of the rate of bone remodeling (32). Whether the increased number of CFU-F observed in the bone marrow of estrogen-deficient mice leads to an increase in other cell types derived from this progenitor (e.g., adipocytes or stromal cells) remains unknown.

The increased osteoblastogenesis and osteoclastogenesis that followed ovariectomy subsided with time in these studies, 

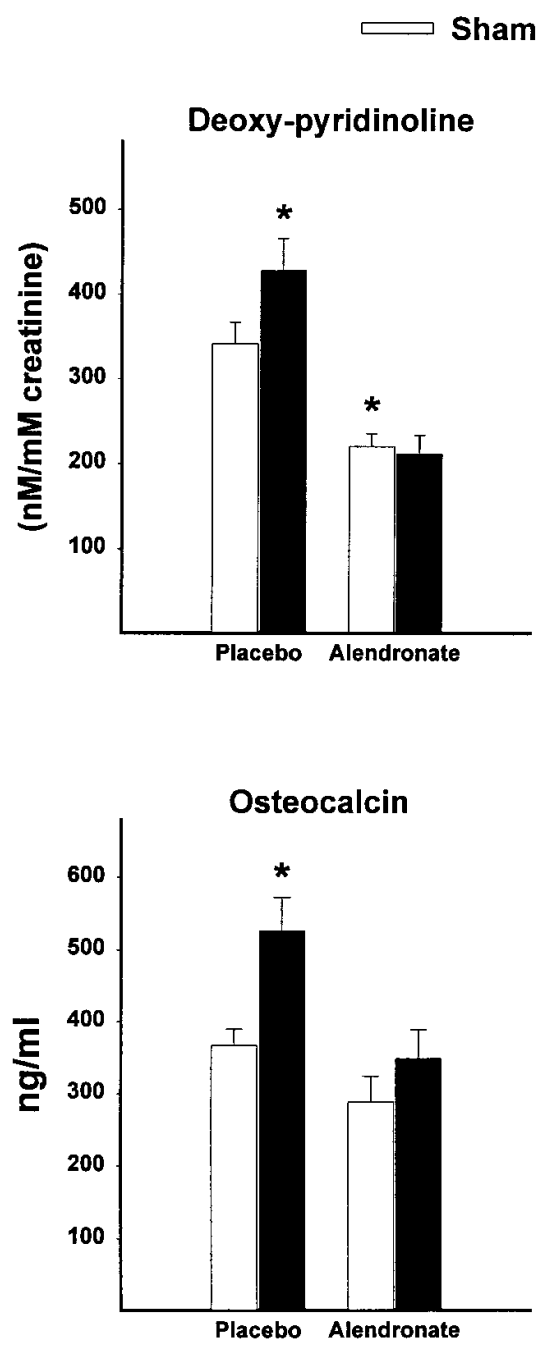
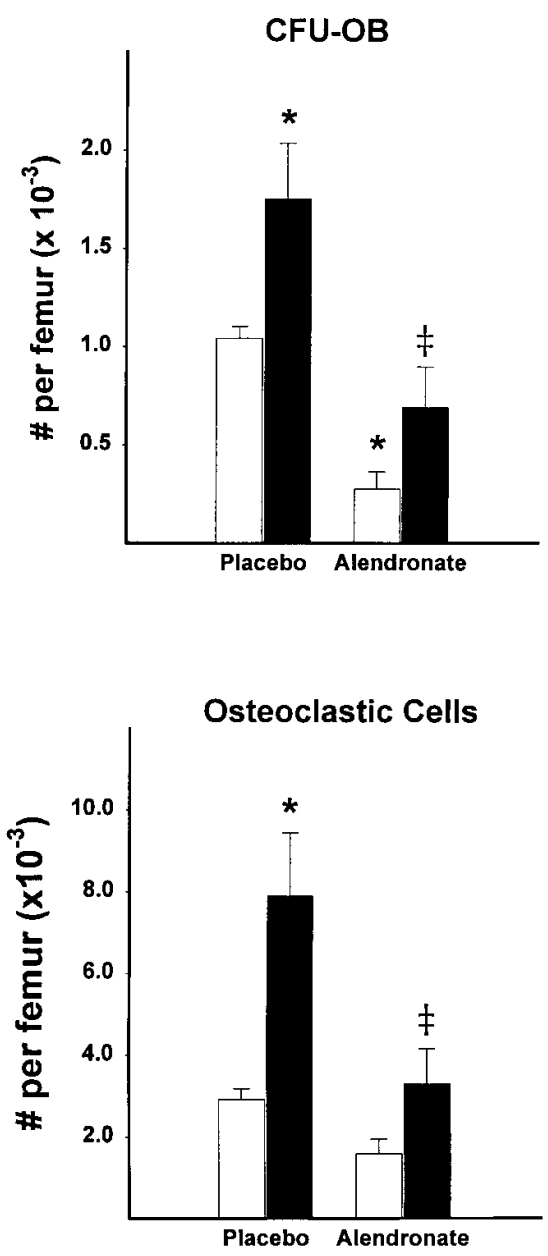

Figure 8. Effect of alendronate on ovariectomyinduced increase in bone cell activity and bone cell progenitors. Mice were injected daily with vehicle or alendronate $(0.25 \mathrm{mg} / \mathrm{kg}$ body weight $)$ beginning $1 \mathrm{~d}$ before sham-operation or ovariectomy. Urinary deoxy-pyridinoline was determined at 2 wk after the operation when ovariectomyinduced bone loss is rapid (Fig. 7). Animals were killed at $4 \mathrm{wk}$ after the operation and serum osteocalcin, osteoclastogenesis, and osteoblastogenesis $(C F U-O B)$ were determined, as described in Methods, using ascorbate-2-phosphate to stimulate osteoblast differentiation and formation of mineralized bone nodules. Data shown are the mean ( \pm SEM) values obtained from 7-10 animals per group. Data were analyzed by ANOVA. $* P<$ 0.05 versus sham-operated vehicle-treated mice, ${ }^{\ddagger} P<0.05$ versus sham-operated alendronatetreated mice. as did osteocalcin levels in the serum and the rate of bone loss. These findings are in agreement with previous studies in rats, indicating that the increased bone remodeling and bone loss caused by ovariectomy subsides with time $(26,27)$. Moreover, they are in agreement with studies in humans indicating that the rapid bone loss associated with increased bone remodeling subsides with time after loss of sex steroids, and is followed by a later stage of slower bone loss (33), and with evidence that the increased bone remodeling at the menopause is attenuated within $10 \mathrm{yr}$ (28). Nevertheless, other studies have indicated that bone loss after menopause may continue unabated throughout life (34).

During normal bone remodeling, the provision of the appropriate number of mature osteoblasts is thought to be controlled by factors, such as TGF- $\beta$, that are released from the bone matrix during its resorption by osteoclasts $(35,36)$. Our finding that administration of alendronate reduced the number of CFU-OB in the bone marrow of sex steroid-sufficient mice is entirely consistent with this idea. Nonetheless, the observation that increased osteoblastogenesis in ovariectomized mice was still present when bone resorption (and thereby release of factors from the bone matrix) was blocked by alendronate, indicates that this cellular change could not have been brought about by this mechanism. Instead, our results strongly indicate that estrogen loss unleashes signals that can stimulate early osteoblast progenitors. However, the ovariectomy-induced increase in osteoblast progenitors in mice receiving alendronate did not lead to increased bone formation, as evidenced by the lack of change in circulating osteocalcin. This is most probably due to the fact that bone formation occurs only at sites of previous resorption in remodeling bone; and because the latter was blocked by alendronate, bone formation could not occur (37). We recognize that we have not excluded the possibility that alendronate might have exerted additional effects on cells of the bone marrow. However, this possibility is very unlikely, as an identical dose of alendronate had no effect on the number of osteoclast precursors in the murine bone marrow in an earlier study (38).

The source and nature of the signals leading to increased osteoblastogenesis unleashed by ovariectomy is only a matter of conjecture at this stage. IL-6-type cytokines have been shown to stimulate the early stages of osteoblast differentiation (39-41); overexpression of leukemia inhibitory factor or oncostatin $\mathrm{M}$ in mice causes increased bone formation $(42,43)$; and IL-6-type cytokines exert antiapoptotic effects on osteoblastic cells $(44,45)$. Thus, it is reasonable to propose, that besides osteoclastogenesis, the increased IL-6 production and increased IL-6-type cytokine responsiveness caused by estrogen 
deficiency (46) is also responsible for stimulating osteoblastogenesis (39).

Because osteoclastogenesis is critically dependent on stromal/osteoblastic cells (5), the increased osteoblastogenesis and osteoclastogenesis in the bone marrow of ovariectomized mice may be interdependent. Studies of mice with defective osteoblast development (SAMP6) have revealed that osteoclastogenesis was also decreased, thus providing evidence for the importance of this dependency in vivo (22). More important, orchidectomy failed to stimulate osteoblastogenesis in these mice; and the expected increase in osteoclastogenesis and the bone loss that occur in mice with normal osteoblastogenesis were blunted in SAMP6 (24). Hence, paradoxical as it may seem, it is possible that the ovariectomy-induced stimulation of mesenchymal cell differentiation towards the osteoblastic lineage plays a role in the increased osteoclastogenesis. Obviously, the increased osteoblast development described here must not be sufficient to meet the demand imposed by the increased osteoclastogenesis and bone resorption that occurs after estrogen loss. Therefore, cellular changes that favor resorption over formation must occur.

In conclusion, the results of this study provide strong support for the contention that the rates of osteoclastogenesis and osteoblastogenesis in the bone marrow are critical determinants of the rates of bone resorption and bone formation, and thereby responsible for the increased rate of bone remodeling in estrogen deficiency. In addition, these studies reveal for the first time that a normally operating mechanism, which assures the coordinated production of osteoblasts in response to the needs generated by osteoclastic bone resorption, is overridden in acute estrogen deficiency by the unleashing of factors that stimulate osteoblastogenesis in a fashion autonomous from the need created by bone resorption. Therefore, the upregulation of osteoblastogenesis after acute estrogen loss is inappropriate for the normal remodeling process.

\section{Acknowledgments}

The authors wish to thank Michael Parfitt (University of Arkansas for Medical Sciences, Little Rock, AR) for advice, and Catherine Smith (UAMS) and Don Paul (Lilly Research Labs, Indianapolis, IN) for technical assistance in the conduct of this work.

This work was supported by Public Health Service grants (P01 AG13918 and AR43003), and the Department of Veterans Affairs.

\section{References}

1. Aubin, J.E., K. Turksen, and J.N.M. Heersche. 1993. Osteoblastic cell lineage. In Cellular and Molecular Biology of Bone. M. Noda, editor. Academic Press, San Diego, CA. 1-45.

2. Roodman, G.D. 1996. Advances in bone biology: the osteoclast. Endocr. Rev. 17:308-332.

3. Bellows, C.G., J.E. Aubin, and J.N.M. Heersche. 1991. Initiation and progression of mineralization of bone nodules formed in vitro: the role of alkaline phosphatase and organic phosphate. Bone Miner. 14:27-40.

4. Van Vlasselaer, P., N. Falla, H. Snoeck, and E. Mathieu. 1994. Characterization and purification of osteogenic cells from murine bone marrow by twocolor cell sorting using anti-Sca-1 monoclonal antibody and wheat germ agglutinin. Blood. 84:753-763.

5. Suda, T., N. Takahashi, and T.J. Martin. 1992. Modulation of osteoclast differentiation. Endocr. Rev. 13:66-80.

6. Parfitt, A.M., C.H.E. Mathews, A.R. Villanueva, M. Kleerekoper, B. Frame, and D.S. Rao. 1983. Relationships between surface, volume and thickness of iliac trabecular bone in aging and in osteoporosis: implications for the microanatomic and cellular mechanism of bone loss. J. Clin. Invest. 72:13961409.

7. Eriksen, E.F., S.F. Hodgson, R. Eastell, S.L. Cedel, W.M. O'Fallon, and
B.L. Riggs. 1990. Cancellous bone remodeling in type I (postmenopausal) osteoporosis: quantitative assessment of rates of formation, resorption, and bone loss at tissue and cellular levels. J. Bone Miner. Res. 5:311-319.

8. Poli, V., R. Balena, E. Fattori, A. Markatos, A. Yamamoto, H. Tanaka, G. Ciliberto, G.A. Rodan, and F. Costantini. 1994. Interleukin-6 deficient mice are protected from bone loss caused by estrogen depletion. EMBO (Eur. Mol. Biol. Organ.) J. 13:1189-1196.

9. Balena, R., B.C. Toolan, M. Shea, A. Markatos, E.R. Myers, S.C. Lee, E.E. Opas, J.G. Seedor, H. Klein, D. Frankenfield, et al. 1993. The effects of 2-year treatment with the aminobisphosphonate alendronate on bone metabolism, bone histomorphometry, and bone strength in ovariectomized nonhuman primates. J. Clin. Invest. 92:2577-2586.

10. Kalu, D.N. 1991. The ovariectomized rat model of postmenopausal bone loss. Bone Miner. 15:175-192.

11. Jilka, R.L., G. Hangoc, G. Girasole, G. Passeri, D.C. Williams, J.S Abrams, B. Boyce, H. Broxmeyer, and S.C. Manolagas. 1992. Increased osteoclast development after estrogen loss: mediation by interleukin-6. Science. 257: 88-91.

12. Bellido, T., R.L. Jilka, B.F. Boyce, G. Girasole, H. Broxmeyer, S.A. Dalrymple, R. Murray, and S.C. Manolagas. 1995. Regulation of interleukin-6, osteoclastogenesis and bone mass by androgens: the role of the androgen receptor. J. Clin. Invest. 95:2886-2895.

13. Girasole, G., R.L. Jilka, G. Passeri, S. Boswell, G. Boder, D.C. Williams, and S.C. Manolagas. 1992. 17ß-estradiol inhibits interleukin-6 production by bone marrow-derived stromal cells and osteoblasts in-vitro: a potential mechanism for the antiosteoporotic effect of estrogens. J. Clin. Invest. 89:883-891.

14. Pottratz, S.T., T. Bellido, H. Mocharla, D. Crabb, and S.C. Manolagas. 1994. 17ß-estradiol inhibits expression of human interleukin-6 promoter-reporter constructs by a receptor-dependent mechanism. J. Clin. Invest. 93:944-950.

15. Ray, A., K.E. Prefontaine, and P. Ray. 1994. Down-modulation of interleukin- 6 gene expression by 17 beta-estradiol in the absence of high affinity DNA binding by the estrogen receptor. J. Biol. Chem. 269:12940-12946.

16. Stein, B., and M.X. Yang. 1995. Repression of the interleukin-6 promoter by estrogen receptor is mediated by NF-kappa B and C/EBP beta. Mol. Cell Biol. 15:4971-4979.

17. Kassem, M., S.A. Harris, T.C. Spelsberg, and B.L. Riggs. 1996. Estrogen inhibits interleukin-6 production and gene expression in a human osteoblastic cell line with high levels of estrogen receptors. J. Bone Miner. Res. 11:193-199.

18. Galien, R., and T. Garcia. 1997. Estrogen receptor impairs interleukin-6 expression by preventing protein binding on the NF-kappaB site. Nucleic Acids Res. 25:2424-2429.

19. Lin, S.-C., T. Yamate, Y. Taguchi, V.Z.C. Borba, G. Girasole, C.A O'Brien, T. Bellido, E. Abe, and S.C. Manolagas. 1997. Regulation of the gp80 and gp130 subunits of the IL- 6 receptor by sex steroids in the murine bone marrow. J. Clin. Invest. 100:1880-1890.

20. Delmas, P.D. 1993. Biochemical markers of bone turnover. J. Bone Miner. Res. 8:S549-S554.

21. Hughes, D.E., K.R. Wright, H.L. Uy, A. Sasaki, T. Yoneda, G.D. Roodman, G.R. Mundy, and B.F. Boyce. 1995. Bisphosphonates promote apoptosis in murine osteoclasts in vitro and in vivo. J. Bone Miner. Res. 10:1478-1487.

22. Jilka, R.L., R.S. Weinstein, K. Takahashi, A.M. Parfitt, and S.C. Manolagas. 1996. Linkage of decreased bone mass with impaired osteoblastogenesis in a murine model of accelerated senescence. J. Clin. Invest. 97:1732-1740.

23. Stuart, A., and J.K. Ord. 1987. Kendall's Advanced Theory of Statistics. Oxford University Press, New York. 223.

24. Weinstein, R.S., R.L. Jilka, A.M. Parfitt, and S.C. Manolagas. 1997. The effects of androgen deficiency on murine bone remodeling and bone mineral density are mediated via cells of the osteoblastic lineage. Endocrinology. 138: 4013-4021.

25. Triffitt, J.T. 1996. The stem cell of the osteoblast. In Principles of Bone Biology. J.P. Bilezikian, L.G. Raisz, and G.A. Rodan, editors. Academic Press, San Diego, CA. 39-50.

26. Wronski, T.J., L.M. Dann, K.S. Scott, and M. Cintrön. 1989. Long-term effects of ovariectomy and aging on the rat skeleton. Calcif. Tissue Int. 45:360-366

27. Li, M., Y. Shen, H. Qi, and T.J. Wronski. 1996. Comparative study of skeletal response to estrogen depletion at red and yellow marrow sites in rats. Anat. Rec. 245:472-480.

28. Stepan, J.J., A. Tesarova, T. Havranek, J. Jodl, J. Formankova, and V. Pacovsky. 1985. Age and sex dependency of the biochemical indices of bone remodeling. Clin. Chim. Acta. 151:273-283.

29. Most, W., L. Schot, A. Ederveen, L. Van der Wee-Pals, S. Papapoulos, and C. Löwik. 1995. In vitro and ex vivo evidence that estrogens suppress increased bone resorption induced by ovariectomy or PTH stimulation through an effect on osteoclastogenesis. J. Bone Miner. Res. 10:1523-1530.

30. Scutt, A., U. Kollenkirchen, and P. Bertram. 1996. Effect of age and ovariectomy on fibroblastic colony-forming unit numbers in rat bone marrow. Calcif. Tissue Int. 59:309-310.

31. Modrowski, D., L. Miravet, M. Feuga, and P.J. Marie. 1993. Increased proliferation of osteoblast precursor cells in estrogen-deficient rats. Am. J. Physiol. 264:E190-E196.

32. Manolagas, S.C., and R.L. Jilka. 1995. Mechanisms of disease: bone marrow, cytokines, and bone remodeling: emerging insights into the pathophys- 
iology of osteoporosis. N. Engl. J. Med. 332:305-311.

33. Parfitt, A.M. 1992. The two-stage concept of bone loss revisited. Triangle. 31:99-110.

34. Eastell, R., P.D. Delmas, S.F. Hodgson, E.F. Eriksen, K.G. Mann, and B.L. Riggs. 1988. Bone formation rate in older normal women: concurrent assessment with bone histomorphometry, calcium kinetics, and biochemical markers. J. Clin. Endocrinol. Metab. 67:741-748.

35. Oreffo, R.O.C., G.R. Mundy, S.M. Seyedin, and L.F. Bonewald. 1989. Activation of the bone-derived latent TGF beta complex by isolated osteoclasts. Biochem. Biophys. Res. Commun. 158:817-823.

36. Hayden, J.M., S. Mohan, and D.J. Baylink. 1995. The insulin-like growth factor system and the coupling of formation to resorption. Bone. 17(Suppl):93S-98S.

37. Hattner, R., B.N. Epker, and H.M. Frost. 1965. Suggested sequential mode of control of changes in cell behavior in adult bone remodelling. Nature. 206:489-490.

38. van Beek, E.R., C.W. Löwik, and S.E. Papapoulos. 1997. Effect of alendronate treatment on the osteoclastogenic potential of bone marrow cells in mice. Bone. 4:335-340.

39. Manolagas, S.C., R.L. Jilka, T. Bellido, C.A. O'Brien, and A.M. Parfitt. 1996. Interleukin-6-type cytokines and their receptors. In Principles of Bone Biology. J.P. Bilezikian, L.G. Raisz, and G.A. Rodan, editors. Academic Press, San Diego, CA. 701-713

40. Bellido, T., V.Z.C. Borba, P. Roberson, and S.C. Manolagas. 1997. Acti- vation of the JAK/STAT signal transduction pathway by IL-6 type cytokines promotes osteoblast differentiation. Endocrinology. 138:3666-3676.

41. Taguchi, T., T. Yamate, H. Mocharla, S.-C. Lin, A. Vertino, P. DeTogni, E. Abe, and S.C. Manolagas. 1996. Interleukin-6 induces osteoblast differentiation in uncommitted embryonic fibroblasts (EF). J. Bone Miner. Res. 11: S101(Abstr.).

42. Metcalf, D., and D.P. Gearing. 1989. Fatal syndrome in mice engrafted with cells producing high levels of the leukemia inhibitory factor. Proc. Natl. Acad. Sci. USA. 86:5948-5952.

43. Malik, N., H.S. Haugen, B. Modrell, M. Shoyab, and C.H. Clegg. 1995. Developmental abnormalities in mice transgenic for bovine oncostatin M. Mol. Cell Biol. 15:2349-2358.

44. Bellido, T., L. Han, R.L. Jilka, and S.C. Manolagas. 1997. gp130/STAT3 activation stimulates the transcription of the cyclin dependent kinase inhibitor p21 ${ }^{\mathrm{WAF} 1, \mathrm{CIP} 1}$ gene in osteoblasts: a prerequisite for the biologic effects of IL-6 type cytokines. J. Bone Miner. Res. 12:S159(Abstr.).

45. Jilka, R.L., R.S. Weinstein, T. Bellido, A.M. Parfitt, and S.C. Manolagas. 1998. Osteoblast programmed cell death (apoptosis): modulation by growth factors and cytokines. J. Bone Miner. Res. In press.

46. Lin, S.-C., T. Yamate, Y. Taguchi, V.Z. Borba, G. Girasole, C.A O'Brien, T. Bellido, E. Abe, and S.C. Manolagas. 1997. Regulation of the gp80 and gp130 subunits of the IL- 6 receptor by sex steroids in the murine bone marrow. J. Clin. Invest. 100:1980-1990. 